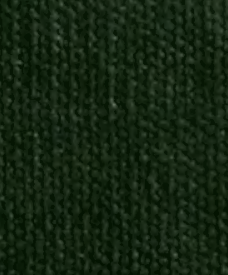




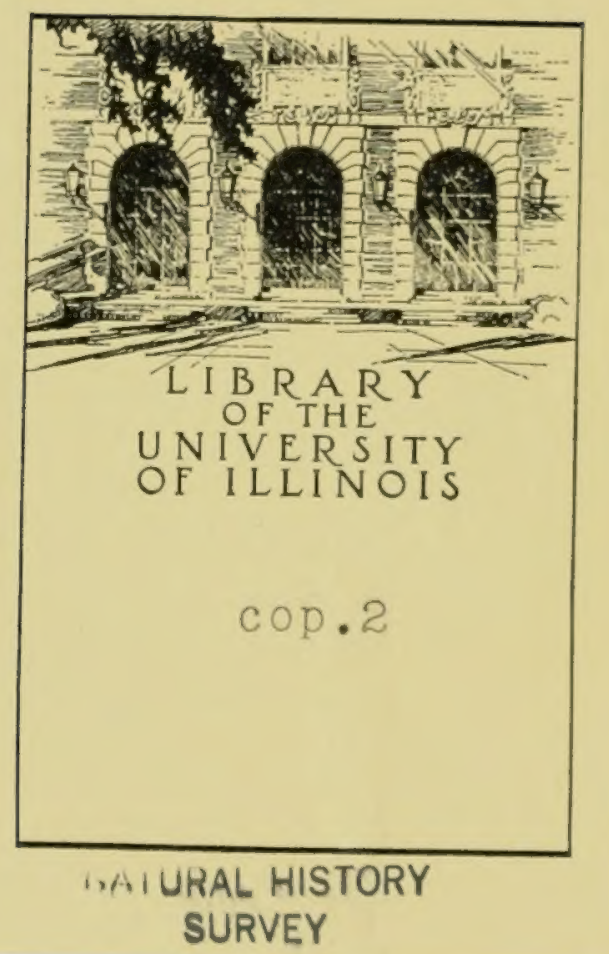






STATE OF ILLINOIS

Otto Kerner, Governor

DEPARTMENT OF REGISTRATION AND EDUCATION William Sylvester White, Director

\section{TECHNIQUES FOR DETERMINING AGE OF RACCOONS}

GLEN C. SANDERSON

Biological Notes No. 45

Printed by Authority of the State of Illinois August, 1961

\section{NATURAL HISTORY SURVEY DIVISION}

Harlow B. Mills, Chief

Urbana, Illinois

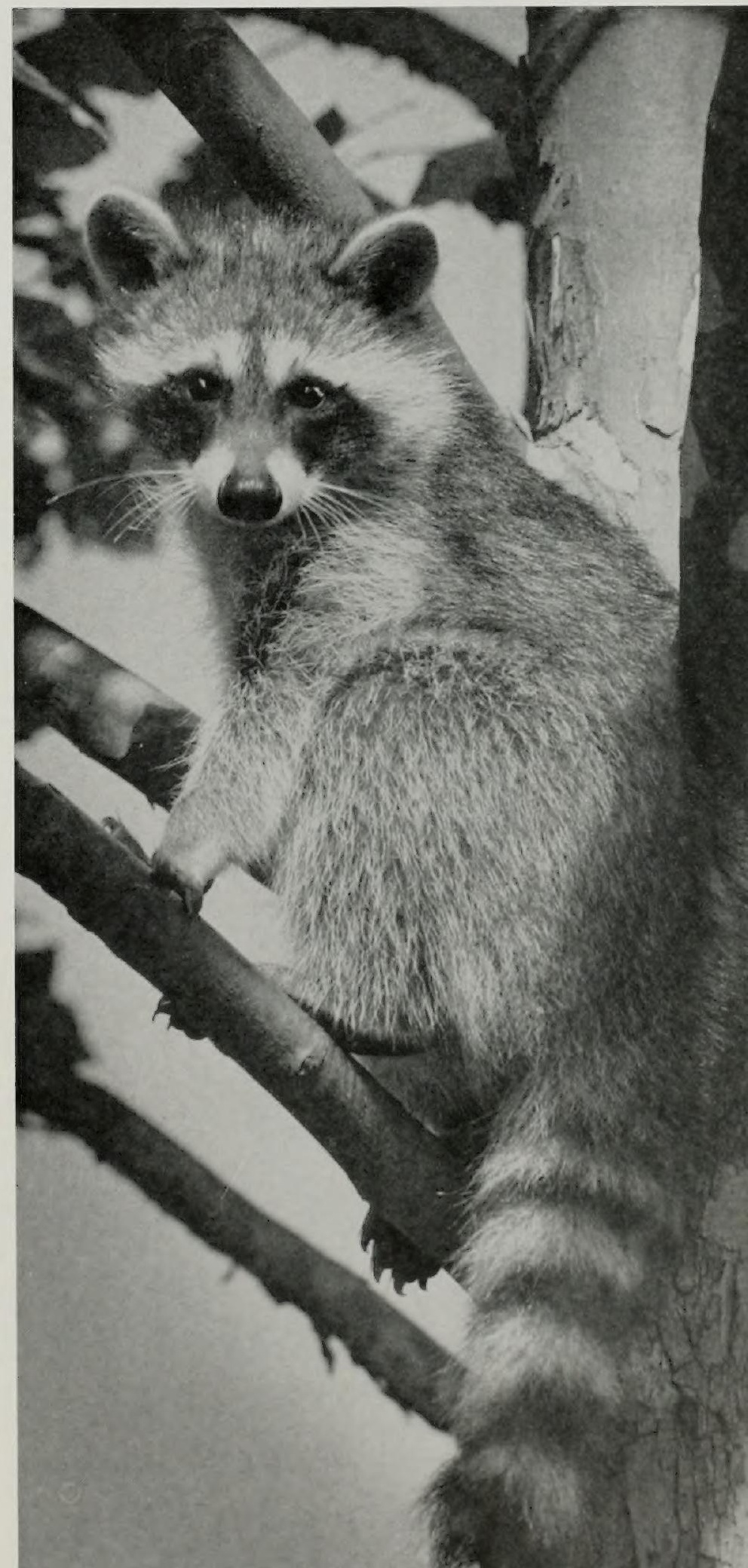




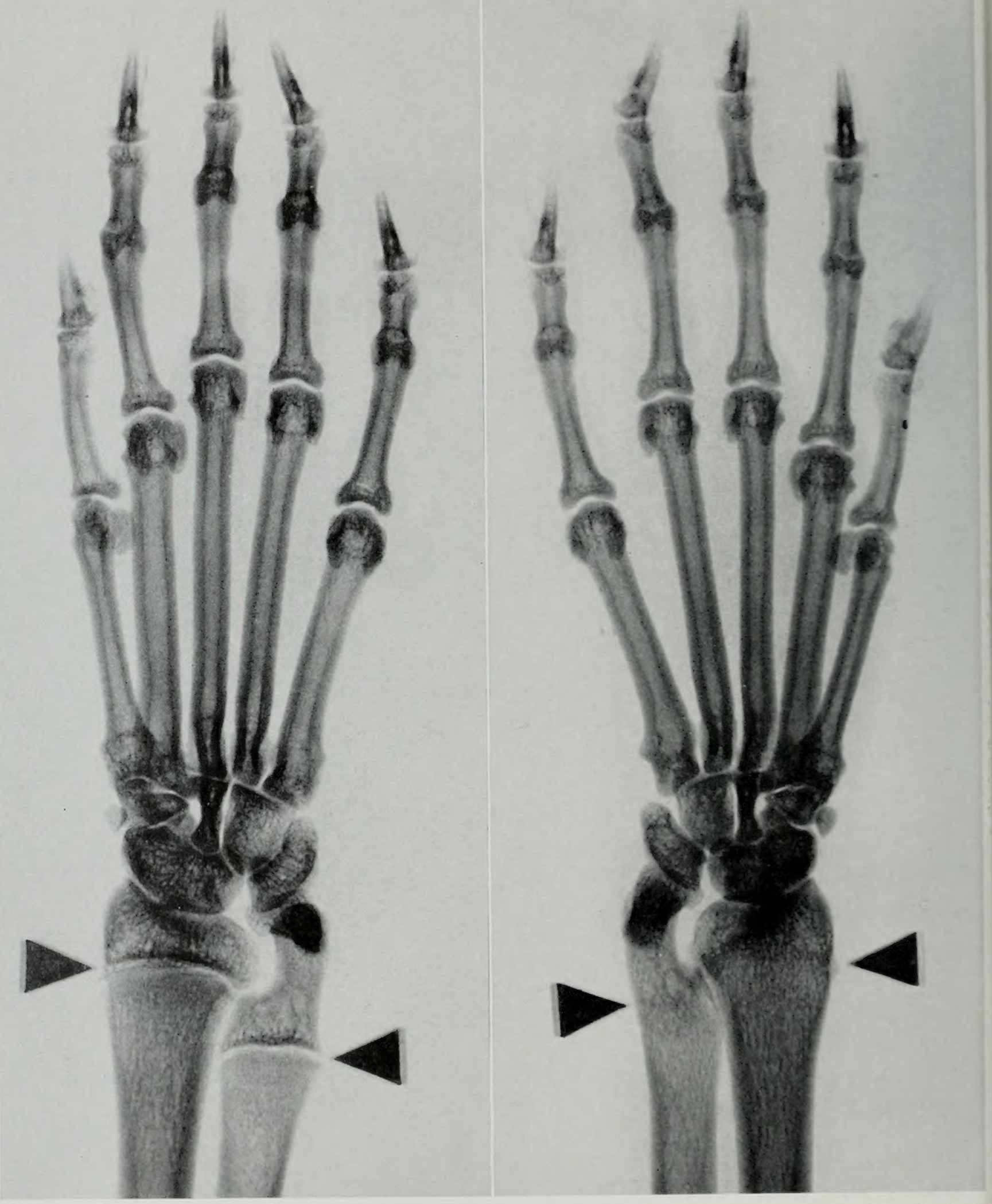

Fig. 1. - X-ray photographs of radii and ulnae from two raccoons. Photograph on the left shows bones of an animal approximately 14 months o'd with broad epiphyses (arrows). Photograph on the right shows bones of an animal approximately 26 months old with closed epiphyses (arrows). 


\section{TECHNIQUES FOR DETERMINING AGE OF RACCOONS*}

\section{GLEN C. SANDERSON†}

For more than a decade, it has been possible to separate both living and dead male raccoons (Procyon lotor) into adult and juvenile classes, from at least the beginning of the hunting season each year through the following January, by examination of the penis (Sanderson 1950:395-6). Also, it has been possible to separate dead males into juvenile and adult classes by the penis bone alone (Sanderson 1950:392-5). A criterion for separating female raccoons into adult and juvenile classes has not been available until recently, when it was demonstrated (Sanderson 1961) that the lens of the eye can be used for age estimation in dead raccoons, both males and females. This criterion is especially useful for determining the month of birth of raccoons less than 1 year old.

The primary purpose of the present paper is to report on one phase of extensive raccoon studies now being made in Illinois: new methods which have been established for separating males and females into juvenile and adult age classes. In this paper, juvenile refers to an animal less than 1 year old and adult to an older animal. A secondary purpose of this paper is to report on progress toward developing methods for estimating the ages of raccoons of both sexes to such a degree that during the hunting and trapping season the animals may be separated into more than two age classes.

\section{ACKNOWLEDGMENTS}

Special acknowledgment is made to Dr. Thomas G. Scott of the Illinois Natural History Survey for his critical review of the manuscript. Thanks are due to several co-workers, Dr. Carl O. Mohr, Dr. Ralph E. Yeatter, and R. I. Smith for advice concerning the presentation of data and to B. J. Verts for live raccoons and parts of dead raccoons; and State Department of Conservation officers Conrad Foley and Loyd Skinner for many live raccoons. The manuscript was edited by James S. Ayars, Technical Editor of the Survey.

\section{MATERIALS AND METHODS}

Several raccoons of known ages, exact or approximate, were kept in outdoor cages at Urbana, and various characteristics associated with age were studied. Some of the animals had been born in captivity; their exact ages were known. Others had been captured as juveniles; their ages at the time of capture were estimated. Most of the captured animals had been taken in Champaign, Edgar, or Piatt counties, in east-central

* A contribution from Illinois Federal Aid Project No. 56-R, the Illinois Department of Conservacion the Unired States Bureau of Spor Fisheries and Wildlife, and the Illinois Natural History Survey, cooperating.

t Associate Wildlife Specialist, Illinois Natural History Survey; for the greater part of this study Sanderson was employed by the Illinois Depart ment of Conservation under terms of the Federal Aid in Wildlife Restoration Act and was assigned to the Illinois Natural History Survey for administrative and technical supervision.
Illinois; some had been taken in Carroll County, in northwestern Illinois.

Studies made on captive animals were supplemented by observations made on raccoons living in the wild. Several juvenile raccoons were live trapped on the Robert Allerton Park study area near Monticello, Piatt County, in east-central Illinois. Their ages were estimated, and the animals were marked and released at the points of capture. When one of these marked animals was killed by a hunter or trapper and made available for examination, it was studied in order to see if there were significant differences between wild and captive raccoons in the characteristics under consideration for estimating ages.

The principal guides used for aging raccoons were, for animals of both sexes, (1) body weight, (2) the degree of ossification of the epiphyseal cartilage of the radius and ulna, fig. 1 , and, for the male, (3) the size and degree of ossification of the penis bone or os baculum. The mean date of birth for raccoons in the northern half of Illinois was used to assign an approximate age to juvenile raccoons of both sexes that were not weighed or that were taken after November 1.

Body weight, the first guide or criterion investigated for aging raccoons, was studied in both captive and wild individuals. Several young raccoons born in captivity were weighed at irregular intervals until they were 6 months of age, and their weights in relation to their ages were plotted on a graph, fig. 2. Each of these young born in captivity was removed from its mother at some time prior to 2 months of age. Weaning at an early age was made necessary by the requirements of another phase of the raccoon studies; young raccoons normally nurse for about 4 months. It is believed that captive and wild raccoons that are nursing show similar rates of gain in weight. The weights of captive young subsequent to weaning showed that the average weight gains were greater for captive than for wild young. Therefore, in the first step in estimating the ages of wild raccoons, only the weights of captives previous to weaning were used.

A line was fitted by eye to the points on the graph representing the weights of the nursing raccoons born in captivity. The weights of these captives took the line on the chart up to 2 pounds. Points representing the weights of captured young raccoons born in the wild and weighing less than 2 pounds at initial capture were placed on the line established for the nursing raccoons. The age of each of the wild animals at capture was estimated by reference to the point at which a vertical line drawn through its weight point intersected the base line of the graph. These wild young were released at the places of capture after they 


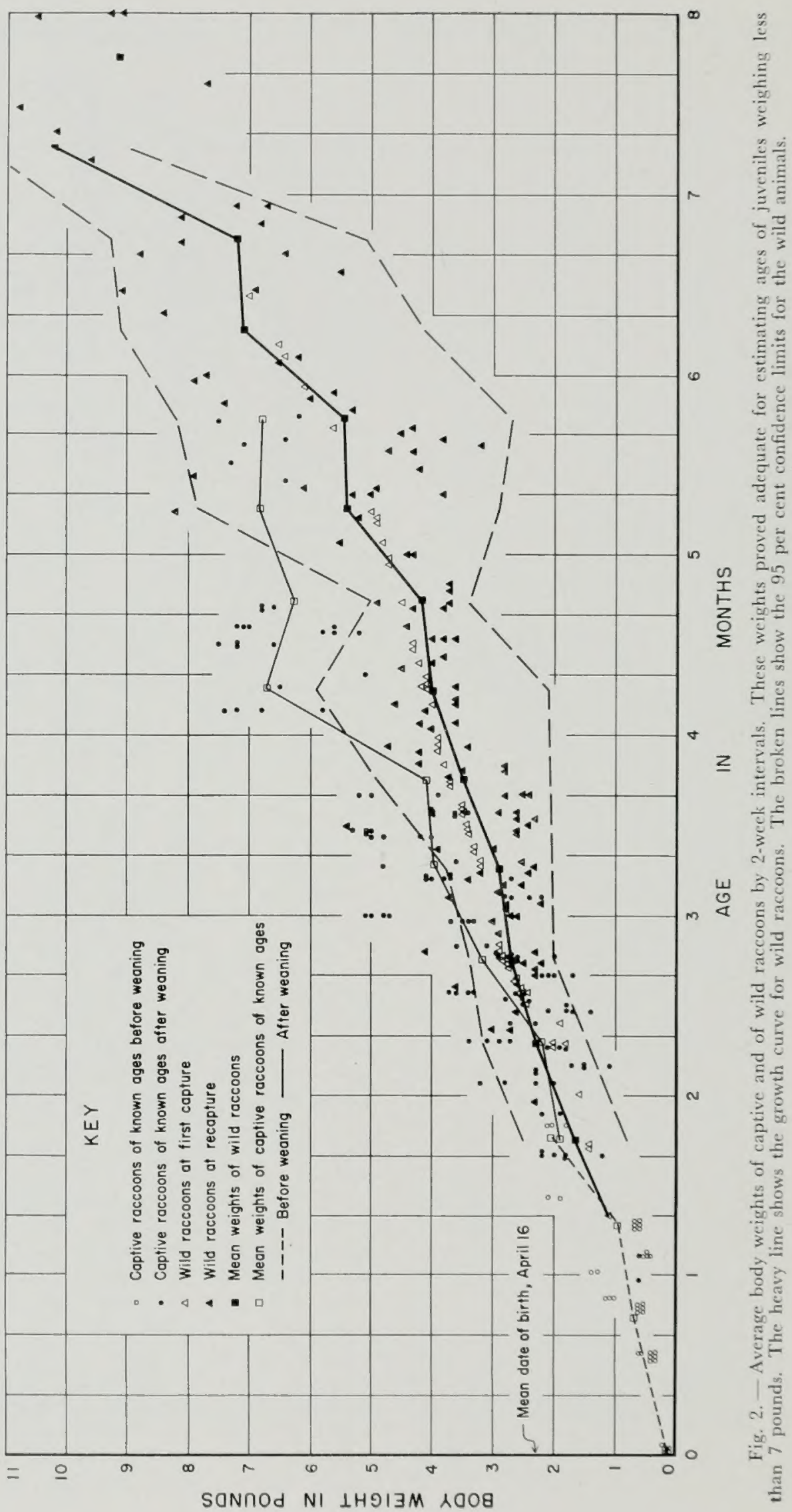


had been marked. They were weighed at each recapture and their weights were plotted on the graph at the proper intervals. All points on the graph up to 3 pounds were then used to construct a new line by eye. The weights of all raccoons which weighed more than 2 but less than 3 pounds the first time they were captured were then placed on the recently established line and the ages of these animals were estimated. These animals also were weighed at each recapture and their weights were plotted on the graph at the proper intervals. All points on the graph up to 4 pounds were then used to construct a new line by eye. A similar procedure was repeated for each 1-pound weight class up to 7 pounds.

The first lines drawn for each 1-pound weight class were then ignored, and a new line was established by plotting the mean weights within each pound class in relation to the mean estimated age of the animals, fig. 2 . The line established in this manner provided the basis for determining the ages for all juvenile raccoons up to 7.0 pounds of weight when taken prior to November 1 . These weight-time limitations were arbitrary, but, up to November 1, juvenile raccoons are rather easily recognized by weight, conformation, pelage, appearance of the nipples in the females, and development of the penis in males (Sanderson 1950:395-6). After November 1 , some juveniles reach adult weights, and some adults lose weight because of critical food conditions at this time and the fact that raccoons may remain in dens and without food for several days during periods of severe weather. Significant weight differences between the sexes were not found. It was concluded that age could be estimated in months, on the basis of body weight, for male and female raccoons weighing 7 pounds or less and caught prior to November 1.

If an animal could not be classified as a juvenile when first caught, its minimal age was determined. For example, a lactating female or an adult male caught in July would have a minimal age of 15 months. In Illinois, raccoons do not breed until they are approximately 10 months of age or older. Because most rascoons in the northern half of Illinois are born during April, this was assumed to be the month of birth when cxact information was not available. Of course, an animal might have been 1 or more years older than its minimal age.

The epiphyseal cartilage, the second criterion investigated as a possible means for estimating age in raccoons, was studied in both living and dead animals. The age classification of epiphyseal cartilages used here is adapted from that of Halc (1949:217) for cottontail rabbits (Sylvilagus foridanus). Unless otherwise indicated, references to epiphyseal cartilage apply only in that of the ulna and the radius.

Epiphyseal closure was studied in several captive raccoons of known ages by photographing their radii and ulnae by X-rays. Photographs were taken at irregular intervals until the epiphyseal cartilage disappeared. Live raccoons were anesthetized prior to being photo- graphed, but no special preparation was needed for the occasional dead raccoon whose epiphyses were photographed. An intraperitoneal injection of pentobarbital sodium (nembutal), at the rate of $1 \mathrm{cc}$. per 4 pounds of body weight, produced deep anesthesia in most raccoons within 5 to 10 minutes. The photographs were taken at a distance of 30 inches. at 92 kilovolts and 10 milliamperes, with an exposure of 4.5 seconds. They were developed by routine methods used for regular film, and the negatives were examined.

Broad bands of epiphyseal cartilage are present in the leg bones of a young raccoon. The cartilage plates are replaced by bony tissue as the raccoon grows older. All epiphyseal plates examined directly or by $\mathrm{X}$-ray photographs were classified as closed, thin, or broad. Closed means that no cartilage is present. Broad indicates a thick plate of epiphyseal cartilage. When bones in this stage of development are cleaned, the epiphysis or head either separates from the shaft or is only loosely attached. In an X-ray photograph, space appears between the head and shaft of the bone. Thin indicates an intermediate condition between closed and broad. In bones in this condition. the head remains attached to the shaft after cleaning, but a groove indicating the presence of cartilage is readily visible. In an X-ray photograph the cartilage appears as a shadow, but there is no space between the head and the shaft of the bone.

Bones from dead raccoons of known ages were cleaned by boiling, and then the epiphyseal plates were examined directly.

Each time the epiphyses of a raccoon were photographed by X-ray, the animal's age, actual for an animal born in captivity and estimated for one born in the wild, was recorded. Not all of the observations were included in tables 4 and 5 . In a raccoon whose epiphyses were photographed more than once, only the maximum age at which broad epiphyses were evident, only the minimum and maximum ages at which thin epiphyses were evident, and only the minimum age at which epiphyseal closure was evident were included in these tables. Several captives were repeatedly photographed by $\mathbf{X}$-rays to determine when the epiphyseal cartilage disappeared. These repeated observations of the same animals made it possible to determine the length of time thin epiphyses were present in individuals.

The penis bone, the third aging criterion investigated, was studied in dead males. When a male. either captive or wild, of known age died, its penis bone was collected. A fresh baculum was cleaned easily by scraping with a pocket knife. A dried baculum was best cleaned by scraping after being boiled in water. After it was cleaned, the baculum was examined for indications of age, including plotographing by X-rays in some cases. The critical points examined for age estimation were degree of ossification of the distal tip and, in some cases, the degree of ossification of the basal end of the bonc. 


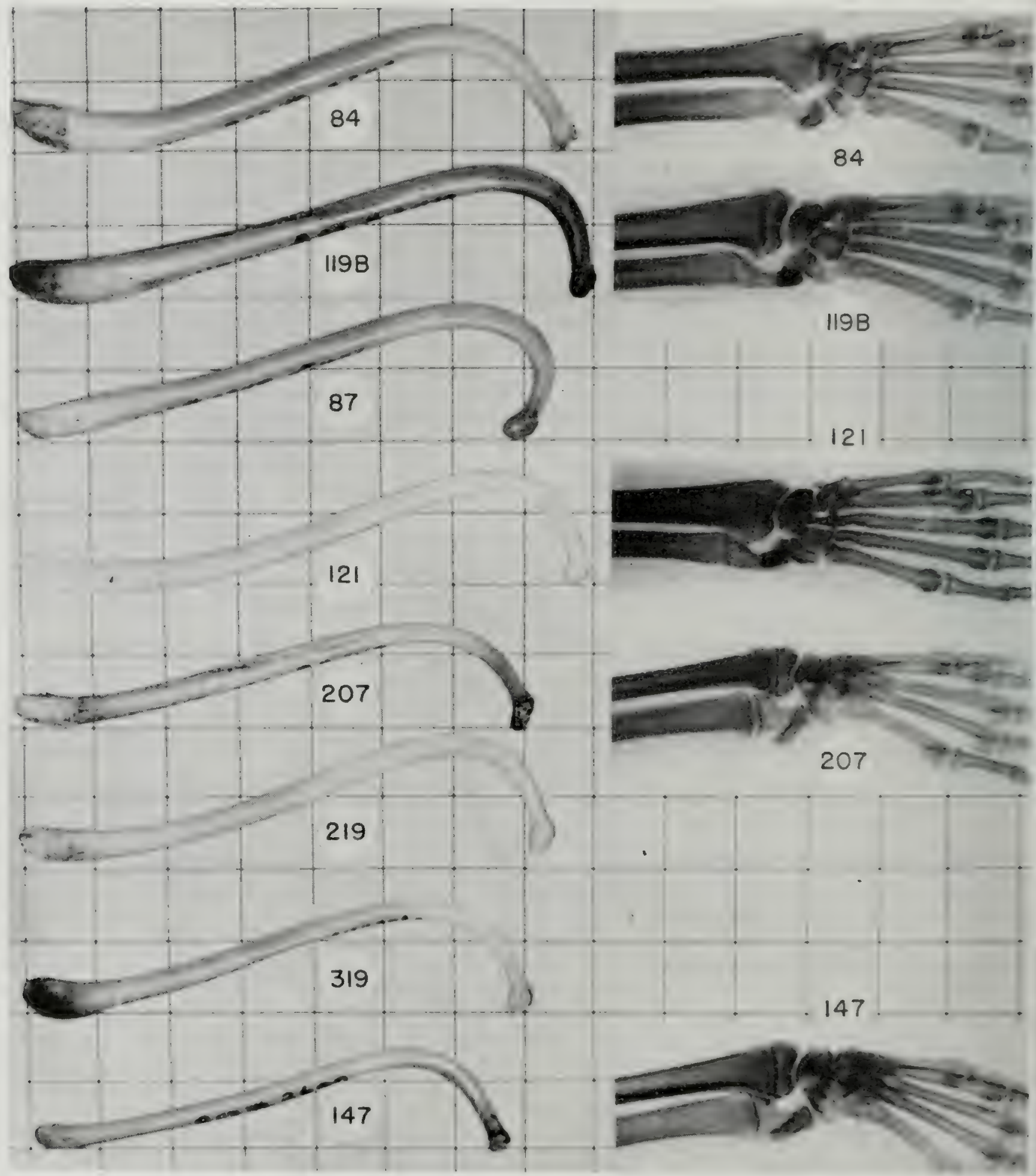

Fig. 3. - Bacula and epiphyses in raccoons of various estimated ages. Grid squares represcnt onc-half inch.

No. 84: captive, 35 months old, adult-typc baculum, closed cpiphyses.

No. 119B: wild, 20 months old, adult-type baculum, thin epiphyses.

No, 87: captive, 19 months old, adult-type baculum.

No. 121: wild, 19 months old, intermediatc baculum, thin cpiphyses.
No. 207: captive, 10 months old, intermediate baculum. broad cpiphyses: reared as a pet until 9 months of

No. 219: wild, 15 months old, intermediate haculum.

No. 319: captive, 12 months old, juvenile-type baculum.

No. 147: wild, 10 months old, juvenile-type baculum, broad cpiphyses. 
A few captive raccoons of both sexes ranging in age from 2 to 17 months were castrated to permit study of the effects of castration on closure of the epiphyses in animals of each sex and on development of the bacula in males.

The average date of birth calculated for raccoons in the wild was used to arbitrarily assign an age to a raccoon found to be juvenile by $\mathrm{X}$-ray of epiphyseal cartilage where (1) the body weight of an animal was not available; (2) the animal weighed more than 7.0 pounds; or (3) the animal was caught after November 1. Actual or approximate birth dates were determined for 17 litters conceived in the wild in the northern half of Illinois during 1958, 1959, and 1960. Four of the 17 litters were born in captivity. Potential birth dates for the other 13 litters were estimated by measuring embryos in females as described by Llewellyn (1953: 321); most of the females examined were found dead along highways. The average date of birth for raccoons in the northern half of Illinois was assumed to be the same as that calculated for these 17 known or estimated dates of birth.

\section{RESULTS}

Most raccoons in the northern half of Illinois are born during April, table 1. The mean birth date, actual or potential, for 17 litters conceived in the wild was April 16; the earliest birth date was March 9, and the latest June 10.

The mean birth date for six litters conceived and born in captivity was April 26. The monthly distribution of these birth dates is shown in table 1 . The earliest birth date for a litter conceived in captivity was March 16, and the latest was June 3.

Although 160 wild female raccoons were examined for pregnancy during January, and several were examined during February, July, and August, table 1, only one pregnant female was observed during these 4 months, and this one, when examined on February 25 , appeared due to give birth in about 3 weeks.

Age Estimation by Weight. - Although there were no significant weight differences between males and females, birth weights and growth rates of young captive raccoons varied among individuals. The weight variations were probably influenced by the number of young per litter, the mother's capacity to produce milk, soil types of the habitats, the availability of food other than milk, and individual genetic differences. Nevertheless, weights were useful in estimating the ages of juvenile wild raccoons weighing up to 7 pounds. The growth rates of 33 captive raccoons, reared in central Illinois up to 2 months of age, table 2, were similar to those reported by Hamilton (1936:136). The average weights of 60 wild raccoons which were caught in live traps two or more times each are presented in table 3. The interval between weighings varied from 1 to 119 days (mean $=30$ days), and the data obtained encompassed weight changes that ranged from a 2.7-pound loss in 63 days to a 6.8-pound gain in 116 days. The weights of these animals ranged from $1 . t$ to 7.0 pounds at the time of initial capture, which occurred between June 28 and October 29.

If body weight indicated that a raccoon was born prior to March 1 (as occasionally happened), March 1 was considered to be the birth date, because few, if any. raccoons are born prior to this date in the northern half of Illinois. As an example, one male weighed 4.2 pounds when caught on July 10 , indicating an age of 4.5 months, fig. 2. 'The weight at date of capture would indicate February 15 as the date of birth. Instead of February 15, the date of birth was recorded as March 1 and the age as 4 months.

Data in table 3 suggest that the growth curve of young raccoons in the wild rises slowly during July, August, and the first half of September in central Illinois when most of these animals are 121 to 180 days of age. Of 87 young animals retrapped one or more times each in the wild during this period, 9 ( 10 per cent) weighed the same as they did when first trapped, and 26 (30 per cent) had lost weight.

The average growth rate of captive young of 2.5-4.5 months of age appears to be somewhat greater than that of wild raccoons of similar ages. This difference in growth rates probably reflects the abundance of high quality food easily available to the captives. When captives were weaned at 2 months of age or younger, weaning was followed by slow growth for about a month, probably reflecting adjustment to the new diet.

Age Estimation by Epiphyseal Development. $\mathrm{X}$-ray photographs and/or direct examinations of radii, ulnae, and some humeri of 45 intact male raccoons, some wild and some captive, revealed that: (1) a broad plate of epiphyseal cartilage was present between the diaphysis, or shaft, and the epiphysis, or head, fig. 3, of each radius and ulna in 35 males ranging from 4 to 15 months of age, 9 being 13-15 months of age, table 4; (2) thin epiphyses were present in 17 males ranging from 13 to 17 months of age, but only 3 males in this group had thin epiphyses after 19 months of age, and 4 had thin epiphyses at 13 months of age; and (3) that the epiphyses closed in 12 males after they were 15 months of age and before they reached 30 months of age. One male had closed epiphyses when he was first $\mathrm{X}$-rayed at 14 months of age. Eight had epiphyses which closed some time after the animals reached 15 months of age and before they reached 20 months of age; the epiphyses of 2 males were closed at the time they were first examined, at 20 and 21 months of age, and the epiphyses of another male were not closed at 27 months of age but were closed at 29 months of age. In this study, 11 of 19 males which were 16-22 months old had closed epiphyses; 8 had thin epiphyses. All males with closed epiphyses were 14 months of age or older. Although there was considerable individual variation, there appeared to be no significant difference in time of epiphyseal closure in wild and captive males. 
Table 1. - Months of birth of raccoons in the northern half of Illinois, as determined by actual births or as estimated from examination of embryos.

Month in Month Designated

Number of Litters Conceived in (aptivity That Were Born in Month Designated
Number of Litters Conceived in the Wild That Had Actual or Potential Birth Date in Month Designated $\uparrow$

January......................... 0

February......................... 0

March......................... 2

April ........................... 1

May........................... 2

June. . . . . . . . . . . . . . . . . . 1

July . . . . . . . . . . . . . . . . . .

August .

Number of Wild Females Examined*

0
0
4
11
1
1
0
0

* Many nonpregnant, adult females examined in the period April-August were lactating.

$\dagger$ Dates of potential birth were estimated as described by Llewellyn (1943) for all but four litters, which were born in captivity.

Table 2. - Average body weights of captive raccoons of known ages, by 2-week intervals; 33 individuals were involved. The average date of birth of these raccoons was April 16.

\begin{tabular}{|c|c|c|c|c|}
\hline $\begin{array}{c}\text { Age } \\
\text { in Days }\end{array}$ & $\begin{array}{l}\text { Number } \\
\text { of Animals } \\
\text { Weighed }\end{array}$ & $\begin{array}{l}\text { Average } \\
\text { Weight in } \\
\text { Pounds }\end{array}$ & $\begin{array}{l}\text { Standard } \\
\text { Deviation of } \\
\text { the Sample }\end{array}$ & $\begin{array}{c}\text { Standard Deviation } \\
\text { of the Mean } \\
\text { (Standard Error) }\end{array}$ \\
\hline \multicolumn{5}{|l|}{ NUKSING } \\
\hline $0-15 \ldots$ & $\ldots$ & 0.1 & 0.05 & 0.02 \\
\hline $16-30 \ldots$ & ... & 0.7 & 0.33 & 0.08 \\
\hline $31-45 \ldots$ & $\ldots 12$ & 0.9 & 0.53 & 0.15 \\
\hline $46-60 \ldots$ & .. 3 & 2.0 & 0.17 & 0.14 \\
\hline \multicolumn{5}{|c|}{ NO LONGER WITH FEMALES } \\
\hline $16-30 \ldots$ & $\ldots$ & 0.6 & $\ldots$ & \\
\hline $31-45 \ldots$ & . & 06 & & \\
\hline $46-60 \ldots$ & $\ldots$ & 1.9 & 0.12 & 0.34 \\
\hline $61-75 \ldots$ & $\ldots 26$ & 2.2 & 0.19 & 0.04 \\
\hline $76-90 \ldots$ & $\ldots$ & 3.2 & 0.17 & 0.91 \\
\hline $91-105 \ldots$ & $\ldots$ & 4.0 & 0.21 & 0.96 \\
\hline $106-120$. & $\ldots$ & 4.1 & 0.27 & 0.72 \\
\hline $121-135$. & $\ldots$ & 6.7 & 0.24 & 0.77 \\
\hline $136-150$. & ... & 6.3 & 0.24 & 0.74 \\
\hline $151-165$. & $\ldots$ & 6.8 & 0.06 & 0.63 \\
\hline $166-180$. & ... & 6.8 & 0.42 & 0.84 \\
\hline
\end{tabular}

Table 3. - Average body weights of wild raccoons that were caught in live traps two or more times each; 60 individuals were involved. The age of each animal the first time it was caught was estimated on the basis of its body weight.

\begin{tabular}{|c|c|c|c|c|}
\hline $\begin{array}{c}\text { Age } \\
\text { in Days }\end{array}$ & $\begin{array}{l}\text { Number } \\
\text { of Animals } \\
\text { Weighed }\end{array}$ & $\begin{array}{l}\text { Average } \\
\text { Weight in } \\
\text { Pounds }\end{array}$ & $\begin{array}{l}\text { Standard } \\
\text { Deviation of } \\
\text { the Sample }\end{array}$ & $\begin{array}{c}\text { Standard Deviation } \\
\text { of the Mean } \\
\text { (Standard Frror) }\end{array}$ \\
\hline 3145 & 1 & 11 & 1 & 1 \\
\hline $46-60 \ldots$ & 4 & 1.7 & 0.43 & 0.21 \\
\hline $61-75 \ldots$ & $\ldots$ & 2.3 & 0.44 & 0.15 \\
\hline $76-90 \ldots$ & 25 & 2.7 & 0.36 & 0.07 \\
\hline $91-105$ & 24 & 2.9 & 0.43 & 0.09 \\
\hline $106-120$ & 28 & 3.5 & 0.73 & 0.14 \\
\hline $121-135$ & 18 & 4.0 & 0.96 & 0.23 \\
\hline $136-150$ & 15 & 4.2 & 0.43 & 0.11 \\
\hline $151-165$ & 14 & 5.4 & 1.24 & 0.33 \\
\hline $166-180$ & 15 & 5.4 & 1.38 & 0.36 \\
\hline $181-195$ & $\cdots$ & 7.1 & 1.05 & 0.37 \\
\hline $196-210$ & $\ldots$ & 7.2 & 1.08 & 0.38 \\
\hline $211-225$ & $\ldots$ & 10.2 & 0.60 & 0.35 \\
\hline $226-240$ & 4 & 9.2 & 1.15 & 0.57 \\
\hline $241-255$ & . & $\cdots$ & & - \\
\hline 256,20 & 1 & -13 & & \\
\hline $271-285$ & 1 & 6.0 & $\ldots$ & \\
\hline $286-300$ & 2 & 8.8 & 0.99 & 0.70 \\
\hline
\end{tabular}


The only exception was one wild female which still had broad epiphyses at approximately 17 months of age, table 5. If the entire carcass of this female had been examined she would have been placed in the adult age class because she was parous. Field data collected in the northern half of Illinois during the 1959-60 and 1960-61 hunting and trapping seasons show somewhat comparable results. Only 3 of 140 females with stimulated nipples (parous females and those which underwent pseudopregnancy) had broad epiphyses. A majority of the adult, wild, nulliparous females, identified by thin or closed epiphyses and no placental scars in their uteri, are 16-22 months of age at this season. In the wild in Illinois, only a few females older than 22 months are nulliparous, because few female raccoons in this state fail to become pregnant in a breeding season after they are more than 1 year of age.
Observations made on seven castrated females were inconclusive, table 5. The epiphyses of one castrated female were thin when the animal was 24 months of age and closed when she was 26 months of age. Those of another castrated female were thin when the animal was 21 months of age and closed when she was 30 months of age. A third castrated female had thin epiphyses when she died at 23 months of age.

In raccoons, epiphyseal cartilage plates in humeri close somewhat later than in radii and ulnae. Two animals had thin plates in their humeri 3 months after the epiphyses of their radii and ulnae had closed. In fous other animals, epiphyseal plates in the humeri were closed 4-9 months after closure in the radii and ulnae: no examinations were made in the intervening periods. It appears that epiphyseal plates in humeri close 3-9 months after they close in the radii and ulnae. Epiphys-

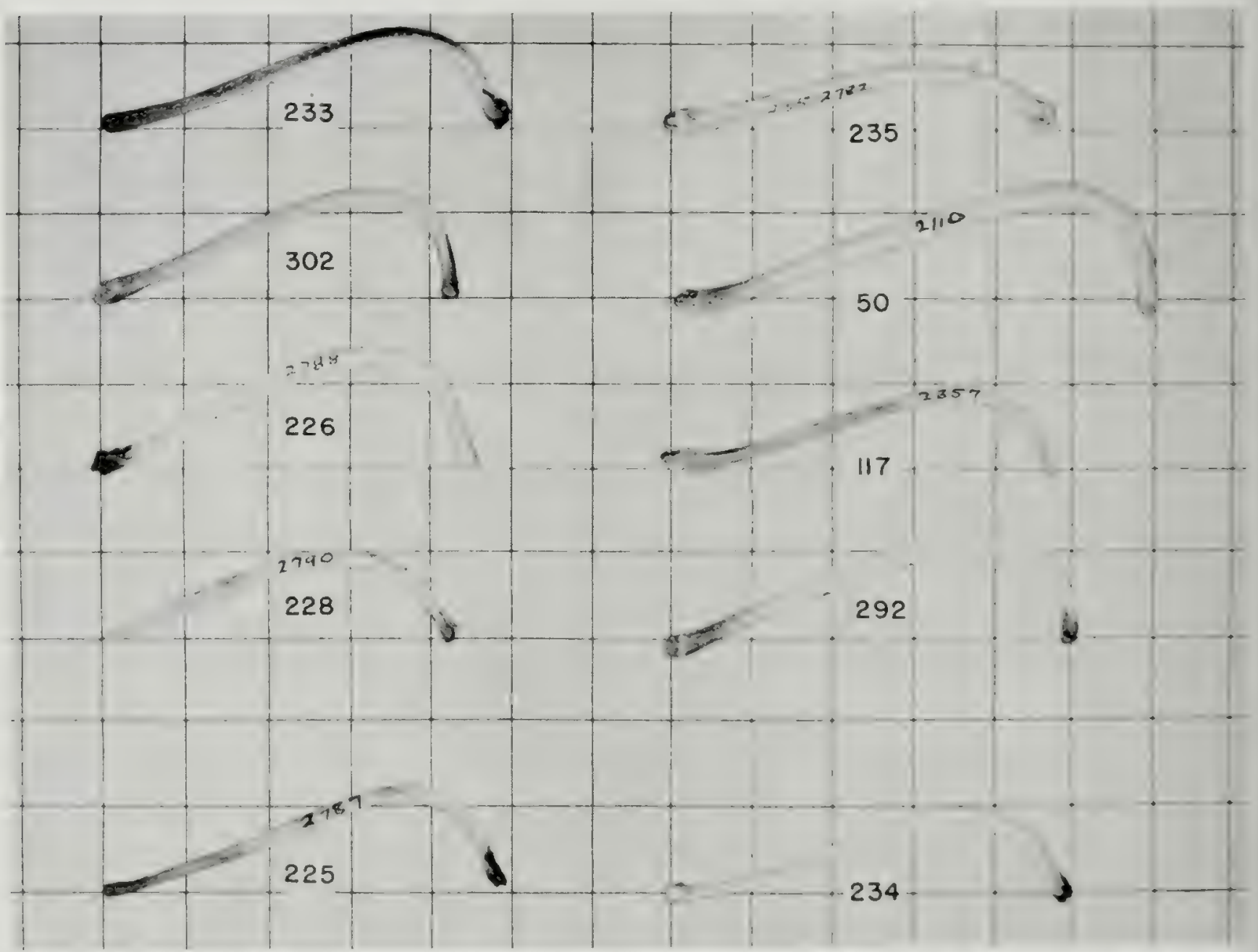

Fig. 4. - Juvenile-type bacula from raccoons 5 to 7 months of age showing the effects of age and castration on development. Grid squares represent one-half inch.

No. 233: captive, 5 months old.

No. 302: wild, estimated 5 months old.

No. 226: captive, 5.5 months old.

No. 228: captive, 5.5 months old.

No. 225: captive, 6 months old, castrated.
No. 235: captive, 6.5 months old.

No. 50: captive, estimated 7 months old.

No. 117: wild, estimated 7 months old.

No. 292: wild, estimated 7 months old.

No. 234: captive, 7 months old, castrated. 
fig. 3, was of no value in determining the age class. The baculum was somewhat porous at both the base and tip; yet the tip appeared to be too much ossified to be that of a juvenile but not sufficiently so to be that of an adult. Captive male No. 207 was approximately 7 months of age when killed. This animal also could not be classified accurately by the baculum. When placed side by side, the bacula, fig. 3 , of these two males appear to be from animals of the same age class, although the bone from male No. 121 is somewhat longer than that from No. 207. Wild male No. 219, approximately 15 months of age, also had a baculum. fig. 3, which could not be classified as adult or juvenile, but the base was slightly more porous than that of male No. 207. Male No. 308, reared as a pet until approximately 5 months of age, had a baculum, fig. 5 , of the adult type at 11 months of age.

The ages of these animals (Nos. 121, 207, 219, and 308) were accurately indicated by the epiphyseal plates of their radii and ulnae. One male (No. 121, fig. 3), approximately 19 months of age, had thin epiphyses, while two males (Nos. 207, fig. 3, and 219, not shown):

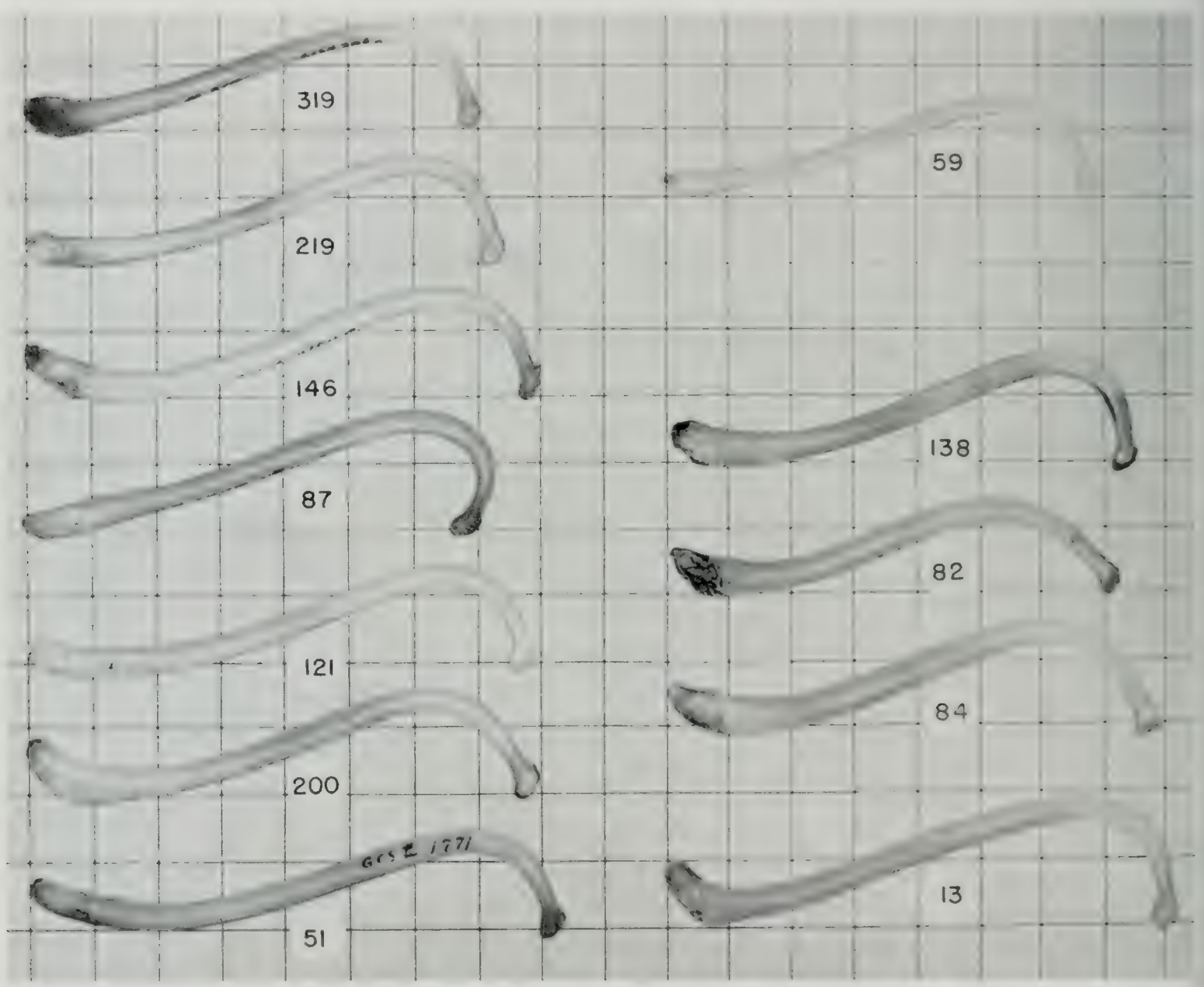

Fig. 6. - Bacula from raccoons 12 to 46 months of age showing the effects of age and castration on development. Grid squares represent one-half inch. All bacula cxcept Nos. $319,219,121$, and 59 are of the adult type.

No. 319: captive, estimated 12 months old, juvenile-type baculum.

No. 219: wild, estimated 15 months old, intermediatctype baculum.

No. 146: captive, estimated 18 months old; reared as a pet until 6 months of age.

No. 87: captive, estimated 19 months old.

No. 121: wild, estimated 19 months old, intermediatetype baculum.
No. 200: wild, estimated 21 months old

No. 51: wild, estimated 21 months old.

No. 59: captive, estimated 22 months old, castrated.

No. 138: captive, estimated 23 months old.

No. 82: captive, estimated $3+$ months old.

No. 84: captive, estimated 34 months old.

No. 13: captive, cstimated 46 months old. 


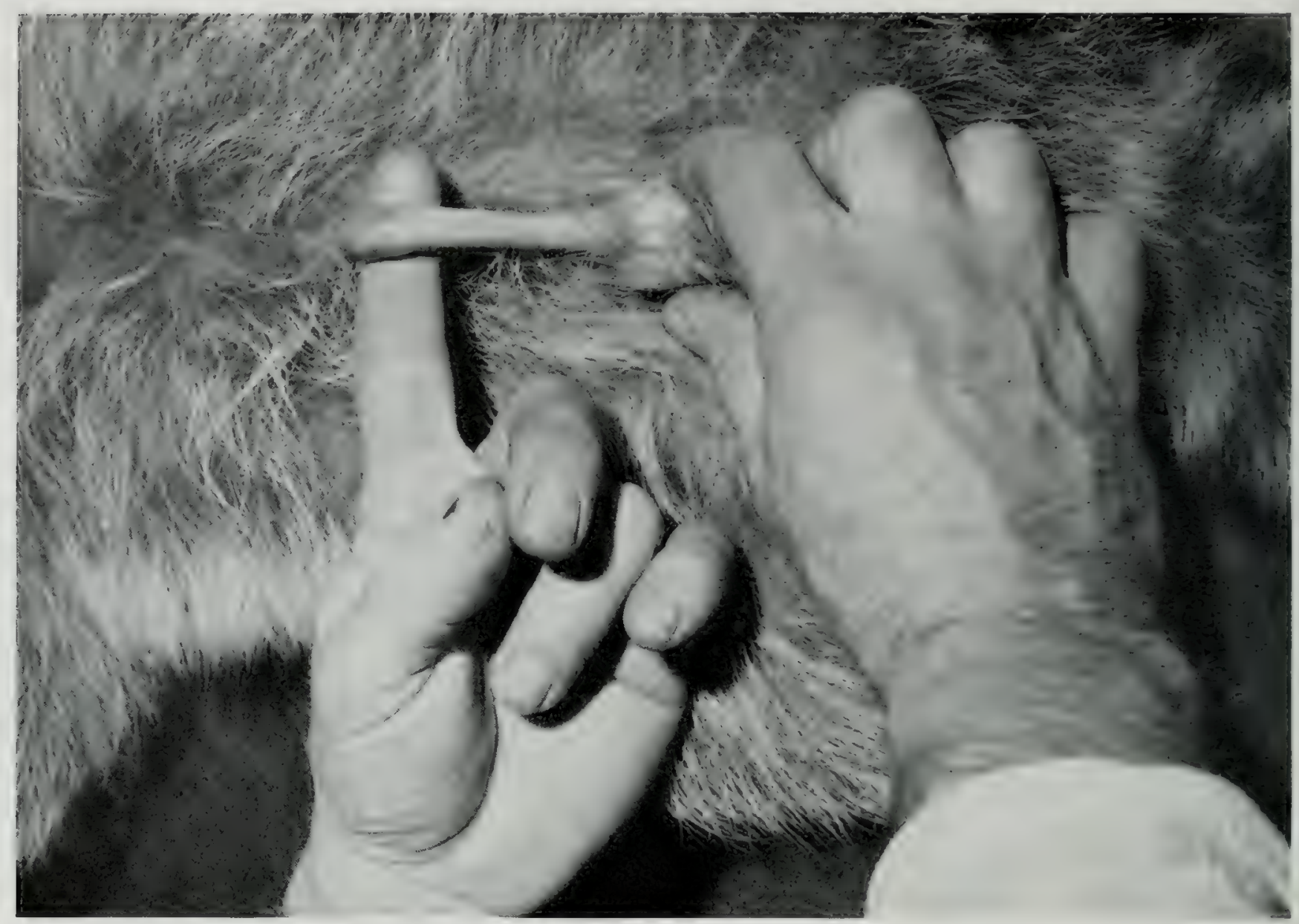

Fig. 8. - Extrusible penis, characteristic of an adult raccoon.

209, fig. 5) is reflected by its baculum, which is much shorter and thinner than the bacula from intact animals 8-11 months of age, fig. 5. Castrated male No, 59, fig. 6 , still had a nonextrusible penis and a small baculum at 22 months of age. The bone of this animal is only slightly longer and heavier than the bone from the castrated raccoon 10 months of age (No. 209, fig. 5) ; it is much shorter and thinner than bacula from intact males 18-23 months of age (Nos. 146, 87, 121, 200, 51, and 138, fig. 6). Although the photograph does not show it well, the baculum from the castrated raccoon 22 months of age (No. 59, fig. 6) was dense like an adult bone and not spongy at the base, as are bacula of similar size from xaccoons 12 months of age or younger.

$\Lambda$ method described several years ago (Sanderson 1950:395-6) for placing males, living or dead, into two age classes based on whether the penis can be easily extruded through the preputial orifice was still found to be useful. For intact males. a nonextrusible penis, fig. 7, indicates a juvenile, while an extrusible penis, fig. 8 , indicates an adult. Lack of the male sex hormone in castrated male No. 59. which was discussed above, resulted in a penis that was nonextrusible when the animal was 22 months of age. 'The effect of pre- cocious sexual development, and presumably higher than average levels of the male sex lormone, on enlargement of the preputial orifice was shown by male No. 207 and male No. 308. Both were reared as pets. Male No. 308 had an extrusible penis at 5 months of age and an adult type baculum at 11 months of age. fig. 5. Male No. 207 had an extrusible penis when first examined at 9 months of age. He had an intermediate type baculum at 10 months of age, fig. 3. Although the penis is not a reliable character for aging male raccoons reared in captivity under all conditions. it is valid for separating wild males into two age classes. juveniles and adults, during the hunting and trapping season in Illinois.

Although ossa clitoridae are present in some female raccoons, they do not indicate age Rinker 19ft). Ages of females may sometimes be estimated on the basis of certain other sexual characters.

For example, most nulliparous females are juvenile and all parous females are adult during the hunting and trapping season in Illinois. Most nulliparous females may be recognized by their tiny, nonpigmented nipples. The nipples of parous females are longer: most of them are dark, but some are nonpigmented (Sander- 
son 1950:397). Observations made on captive raccoons indicate that virgin females which become pseudopregnant have nipples indistinguishable from those of parous females. These animals may be distinguished from parous females by the lack of placental scars in their uteri. Few of these animals are found in the wild; however, they do occur, and the only way they can be separated from the parous females is by an examination of the uteri. During four recent fur seasons in Illinois (1956-1959), uteri from 207 females that appeared to be parous on the basis of nipple development were examined, and 7 ( 3 per cent) had no placental scars.

\section{DISCUSSION}

Petrides (1959:249) reported that raccoons "in their first winter definitely can be identified as such where $X$ rays of the distal ends of the radium and ulna disclose the epiphyses to be distinct and not fused with the shafts of those bones. Animals in their second and subsequent winters have epiphyses joined with the diaphyses." Data presented in the present paper indicate that this conclusion needs modification for application in Illinois. Of the Illinois raccoons examined during hunting and trapping seasons, all individuals with broad epiphyseal plates were in their first winter except one female, and all those with no epiphyseal cartilage were 16-22 months of age or older; however, several animals 16-22 months of age, and some even older, had thin epiphyses, which presumably would place them in their first winter according to the finding of Petrides, who apparently did his research on Ohio raccoons.

All male raccoons and 44 of 45 female raccoons with broad epiphyses were 15 months of age or younger at the time of examination, but 82 per cent of the males with thin epiphyses were 13-19 months of age and 61 per cent of the females with thin epiphyses were 14-19 months of age. Some males still retained thin epiphyses when 27 months of age, and one female with thin cpiphyses was at least 42 months old. Presumably, all of these animals would be placed "in their first winter" by Petrides' method of aging.

The hunting and trapping season for raccoons in Illinois has been within the period October 15-January 31 for the past several years. Many other midwestern states have open seasons covering approximately the same period. Because, in the northern half of Illinois, most raccoons are born in April and few, if any, earlier than March or later than June, table 1, the raccoons encountered here during the hunting and trapping season are either juveniles of about $4-10$ months of age or adults 1 or more years older. No juveniles are more than 11 months old at the end of the hunting season. Rarely are adults less than 15.5 months old at the beginning of the hunting season. The earliest age at which broad epiphyses were found to disappear in northern Illinois raccoons was 13 months, tables 4 and 5. The oldest age at which they were observed was, with one exception, 15 months, table 5. The exception, a female of 17 months, was parous, and her elongated nipples identified her as an adult.

Thus, during the hunting and trapping season, the epiphyseal plates of the radii and ulnae give an almost infallible method for identifying northern Illinois raccoons, both males and females, both living and dead animals, as juveniles or adults. With few exceptions, any raccoon found with broad epiphyses during the hunting and trapping season in the northern half of Illinois is a juvenile; any raccoon found without broad epiphyses is an adult. Examination of entire animals will help to eliminate the few incorrect age classifications that might result if classification were based on epiphyses alone.

Although the epiphyseal plates provide a useful method for aging both male and female raccoons, living or dead, in all but a few cases classification to juvenile or adult in dead males can be more easily accomplished by examining the bacula.

Bacula from captive and from wild raccoons generally showed similar rates of development, although there was considerable individual variation in size and conformation, figs. 4-6. When the rate of development differed between captive and wild raccoons, the more rapid rate occurred in the captive animals. Perhaps the extra illumination and more nutritious diet given some males reared as pets are responsible for precocious sexual development and result in earlier development of the penis bone. Observations made on captive males indicate that those males which are sexually mature in their first year tend to have bacula which approach the adult condition. The penes of such males are extrusible at earlier ages than are those of males which are not sexually mature until nearly 2 years of age.

In addition to affecting the development of the baculum, castration in males may delay closure of the epiphyseal cartilage slightly, but this delay is not as pronounced as the delay in the development of the haculum. Determination of the effects of castration on epiphyseal closure merits further study.

The time of closure of epiphyses in females is close to that in males; however, epiphyseal closure occurs later in some females than in males or in other females. tables 4 and 5. Closure may be later in females that mate for the first time when approximately 10 months of age than in those that mate for the first time when approximately 22 months of age. Although some evidence supports this possibility, the data are insufficient to be conclusive.

\section{SUMMARY}

1. Several raccoons of known ages were kept in outdoor cages and various characteristics associated with age were studied: body weight, degree of ossification of the epiphyseal cartilage of the radius and ulna, and. for the male, the size and the degree of ossification of the penis bone. 
2. A graph based on weights of raccoons of known ages was constructed. Weights on the graph were used as guides for estimating the ages of wild raccoons weighing less than 7 pounds.

3. X-ray photographs were made of the radii and ulnae of raccoons of known ages. Photographs showing the condition of the epiphyses (broad, thin, or closed) were used as guides for aging wild raccoons, both male and female, live and dead.

4. Penis bones of dead males of known ages were collected and studied. Size and degree of ossification of these bones were used as guides for aging wild raccoons.

5. The average date of birth calculated for raccoons in the wild was used to arbitrarily assign an age to a raccoon found by X-ray of epiphyseal cartilage or other aging method to be a juvenile where (1) the body weight was not available, (2) the aninal weighed more than 7 pounds, or (3) the animal was caught after November 1. The average date of birth for 17 litters conceived in the wild in the northern half of Illinois was April 16; the carliest date was March 9, the latest June 10.

6. No significant weight differences were found between males and females of the same ages, even though birth weights and growth rates differed among individuals.

7. Thirty-five of 35 intact male raccoons with broad epiphyses were 15 months of age or less; 14 (82 per cent) of 17 males with thin epiphyses were 13-19 months of age. Eleven of 13 males (85 per cent) with closed epiphyses were 16-21 months of age.

8. Forty-four of 45 intact female raccoons with broad epiphyses were 15 months of age or less; 1t (61 per cent) of 23 females with thin epiphyses were 14-19 months of age, and 1 with thin epiphyses was 31 months of age. Six females 19-30 months of age had closed epiphyses. In two additional females the epiphyses closed when one was a minimum of 39 months and the second a minimum of 42 months of age.

9. The condition of epiphyses during the hunting and trapping season in Illinois was found to furnish an adequate means for separating raccoons, both males and females, living and dead, into two age groups, juveniles and adults.

10. The size and condition of penis bones, as described in a previous study, were found useful in distinguishing juveniles from adults in dead males.

11. Castration of young males resulted in relatively slow growth and abnormal development of the bacula due to lack of the male sex hormone and appeared to have a slight effect on the age at which the epiphyses closed. The effect of castration on the baculum was first apparent when an animal was between 7 and 10 months of age.

12. A method of aging described several years ago and based upon whether the penis can be easily extruded through the preputial orifice was still found to be useful in distinguishing adults from juveniles in living and dead males during the hunting and trapping season.

13. All parous females examined during the hunting and trapping season in Illinois were adults.

14. Seven females which would have been classified as parous on the basis of the nipples alone had no placental scars. These were probably animals which became pseudopregnant during the first mating season following their birth.

15. Although the epiphyseal plates were found to provide a useful method for aging both male and female raccoons, living and dead, in all but a few cases classification to juvenile and adult in dead males can be more easily accomplished by examining the bacula.

\section{Hale, James $\mathbf{B}$.}

\section{LITERATURE CITED}

1949. Aging cottontail rabbits by bone growth. Jour. Wildlife Mgt. 13(2):216-25.

Hamilton, W. J., Jr.

1936. The food and breeding habits of the raccoon. Ohio Jour. Sci. 36:131-40.

Llewellyn, Leonard M.

1953. Growth rate of the raccoon fetus. Jour. Wildlife Mgt. 17(3):320-1.

Petrides, George A.

1959. Age ratios in raccoons. Jour. Mammal. $40(2): 249$.

Rinker, George C.

1944. Os clitoridis from the raccoon. Jour. Mammal. 25(1):91-2.

Sanderson, Glen C.

1950. Methods of measuring productivity in raccoons. Jour. Wildlife Mgt. 14(4):389-402.

Sanderson, Glen C.

1961. The lens as an indicator of age in the raccoon. An. Midland Nat. 65(2):481-5. 


